\title{
Evaluation of Ceramic Inlay Leakage Cemented with Adhesive Materials. An In Vitro Study
}

Magdalena Rączkiewicz ${ }^{1 *}$, Adrianna Rosochacka1, Dariusz Zasada ${ }^{2}$ and Karolina Mazurek ${ }^{2}$

${ }^{1}$ Department of Prosthodontics, Faculty of Dentistry, Medical University of Warsaw, Poland

${ }^{2}$ Department of Chemistry and New Technologies, Military University of Technology, Jaroslaw Dabrowski, Warsaw, Poland

\begin{abstract}
Improvements in porcelain material have influenced the more frequent use of this material in tooth restoration. Researchers are constantly searching for the most efficient solution to bond restoration with dental hard tissues. The aim of this study was to examine the presence of interfacial hybrid layer gaps in the adhesive bond between the ceramic material and dental tissues immediately after cementation.

Thirty human third molars were divided into three experimental groups. In each of the teeth, a cylinder-shaped Black's Class 1 cavity was prepared. An IPS e.max inlay was made by lost wax casting. In order to bond the inlay with the tooth structures, three composite cements were used: Multilink Auto mix, Rely X Ultimate Clicker and selfetching, self-adhesive Rely X U200 Auto mix. After cementation, dental micro sections were taken in order to perform microscopic observations. The final stage of the study consisted of evaluation and measurements under $5 x$ and $10 x$ magnifications with a Nikon MA 200 light microscope.

The outcome of this study indicates differences in the adhesion of the cement to both the dental hard tissue and ceramics. The finest bonding between cement and ceramic was obtained when Multilink Auto mix was used. Also, Rely X U200 Auto mix gave satisfactory results. The least acceptable adhesion of cement to ceramic occurred when Rely X Ultimate Clicker was used.

Based on comparative studies, it may be concluded that self-adhesive cements indicate significantly lower bonding quality in comparison to cements with their own bonding systems. Despite more complex adhesive procedures, multistage bonding systems demonstrate better bonding.
\end{abstract}

Keywords: Microleakage; Ceramic inlay; Hybrid layer

\section{Introduction}

Improvements in porcelain material strength and aesthetics influenced the more frequent use of this material in tooth restoration with successful results for both the clinician and the patient [1]. The use of such restoration requires the proper selection of reconstructive materials and cement. Furthermore, clinical trials show that adhesive cements exhibit favorable aesthetic properties in comparison with conventional materials and this kind of bonding results in satisfying mechanical properties as well. Their success depends on how well the bonding with both dental hard tissues and ceramic material is [2]. Due to a large variety of bonding systems, their components, and application techniques, manufacturers and research centers are constantly searching for the most efficient solution to bond composite materials with dental hard tissues. Clinicians in their day-to-day practice face these numerous options when trying to choose the best one.

The bonding systems, in accordance with their components, may be divided into three categories: multi-bottle adhesives, single-bottle adhesives, self-etch adhesives [1]. In addition, there is another ongoing discussion about the bonding mechanism: etch-and-rinse systems or self-etching systems [1].

Adhesive cementation is the most demanding procedure of prosthetic treatment when using ceramic restorations. The increasing importance of luting procedures that promote adhesion, durability and aesthetics, requires careful treatment. This finishing stage of treatment is subject to many difficulties such as polymerization shrinkage which might result in gap formation, leakage, recurrent caries, and pulp irritation [3]. While fixing the inlay, onlay or laminated veneer, a volumetric contraction varying between $1.5 \%$ and $5 \%$ can be observed. This results in the development of internal stresses, which shortens the clinical lifetime of restoration adhesion [4]. The detrimental effect of marginal gap formation cannot be offset even with the use of fluoride-releasing adhesives or restorative materials that prevent demineralization along cavity margins [5]. Currently the polymerization shrinkage of contemporary dental materials is impossible to be eliminated, it can only be reduced. Thus, only precise sealing ensures long-term durability of fixed restorations in the oral cavity.

The aim of the study was to examine the presence of interfacial hybrid layer gaps in the adhesive bond between the ceramic material and dental tissues immediately after cementation.

\section{Materials and Methods}

Thirty human third molars, free of caries, were examined. In each a cylinder-shaped Black's Class 1 cavity was prepared using a diamondcoated drill and turbine tip with water cooling.

Cylinder shape inlays were prepared in accordance to heat pressed

*Corresponding author: Magdalena Rączkiewicz, Postgraduate Student at the Department of Prosthodontics, Faculty of Dentistry, Medical University of Warsaw, Kremerowska, 5/12 31-130 Kraków, Poland, Tel: 509845078; E-Mail: mm.raczkiewicz@gmail.com

Received: November 09, 2015; Accepted: November 19, 2015; Published: December 02, 2015

Citation: Rączkiewicz M, Rosochacka A, Zasada D, Mazurek K (2015) Evaluation of Ceramic Inlay Leakage Cemented with Adhesive Materials. An In Vitro Study. J Bioengineer \& Biomedical Sci 6: 173. doi:10.4172/2155- 9538.1000173

Copyright: $\odot 2015$ Rączkiewicz M, et al. This is an open-access article distributed under the terms of the Creative Commons Attribution License, which permits unrestricted use, distribution, and reproduction in any medium, provided the original author and source are credited. 
technique for IPS e.max Press ceramic (Ivoclar Vivadent). The inlay molds made of modeling wax were made into a cylinder shape of $5 \mathrm{~mm}$ diameter and $2 \mathrm{~mm}$ thickness. To each cylinder sprues were attached. The IPS e.max inlay was made by lost wax casting. After the pressing process the sprues were cut off and discs were polished. Then the glazing material was applied in a covering layer and the glaze firing process conducted, as all-ceramic inlays are routinely prepared.

Three experimental groups were created, each consisting of ten teeth. Three composite cements were used in the study (Table 1).

The first group was treated with Multilink Auto mix cement with double-bottle bonding system, which contains self-etching Primer $\mathrm{A}$ and $\mathrm{B}$. The inlay molds were etched with $5 \%$ hydrofluoric acid for 20 seconds, then rinsed with water spray and dried with blown air. Monobond Plus was applied to the restorations for 60 seconds and then dispersed with a strong stream of air. Primer A and B were mixed in a 1:1 ratio and then scrubbed for 30 seconds to enamel and dentine using a micro brush. The excess was dispersed with blown air. Multilink Auto mix was placed on the restoration directly with the mixing tip, and the restoration was placed in the cavity. It was light-cured for three seconds, then the excess was removed and all the margins were lightcured for 20 seconds.

Rely X Ultimate Clicker cement with one-bottle bonding system was used to fix the inlays in the second group. The restorations were etched with 5\% hydrofluoric acid for 60 seconds and rinsed with a hard stream of water. Then self-etch Single Bond Universal was applied using the micro brush for 20 seconds and then dispersed with air stream. Enamel was etched with $36 \%$ phosphoric acid for 15 seconds, then rinsed with a hard stream of water and dried with blown air. Single Bond Universal was applied to enamel and dentine with a micro brush for 20 seconds and dispersed for five seconds with blown air. Rely X Ultimate Clicker cement was applied directly from the mixing tip on the restoration surface. The inlays were seated in place, the excess was removed, and the margins were light-cured for 20 seconds.

Despite Rely X Ultimate Clicker being used with self-etching Single Bond Universal, it is recommended to etch the enamel for 15 seconds before bonding. This procedure with selective etching of enamel replaces the etch and rinse procedure.

The third group was treated with self-etching, self-adhesive Rely X U200 Auto mix cement. The cement was mixed and applied to the tooth cavities. Then the inlays were seated in place, the excess was removed, and margins were light-cured for 20 seconds. Each of the cements used is dual-cure.

After cementation, dental micro sections were taken in an optical laboratory in order to perform microscopic observations. All samples were mechanically polished using a Struers polishing machine with abrasive papers of successively decreasing granulation.

The final stage of the study consisted of evaluation and measurements under $5 x$ and 10x magnifications with a Nikon MA 200 light microscope equipped with a camera and computer image analysis software, allowing conduct of the stereological study.

\begin{tabular}{|c|c|c|c|}
\hline & Multilink Automix & $\begin{array}{c}\text { Rely X Ultimate } \\
\text { Clicker }\end{array}$ & Rely x u200 Automix \\
\hline Curing mode & Dual-cure & Dual-cure & Dual-cure \\
\hline $\begin{array}{l}\text { Bonding system } \\
\text { used }\end{array}$ & $\begin{array}{l}\text { Multilink Primer } \\
\qquad A+B\end{array}$ & $\begin{array}{l}\text { Single Bond } \\
\text { Universal }\end{array}$ & Self-adhesive cement \\
\hline
\end{tabular}

Table 1: Characteristics of cements used in the study.

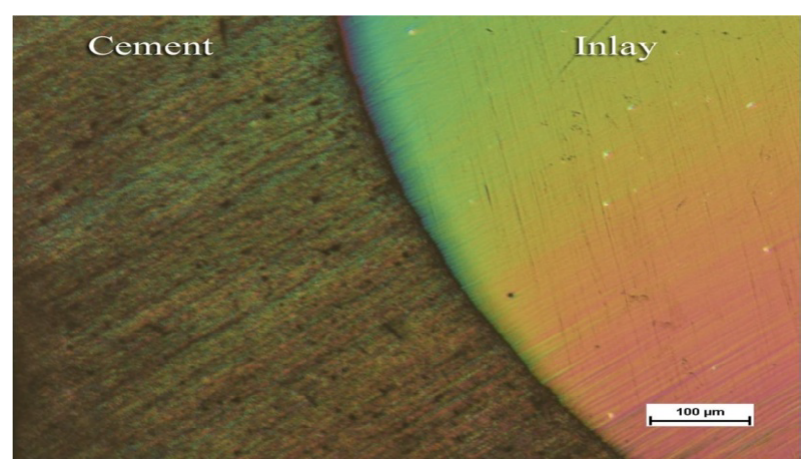

Figure 1: Hybrid layer gap.

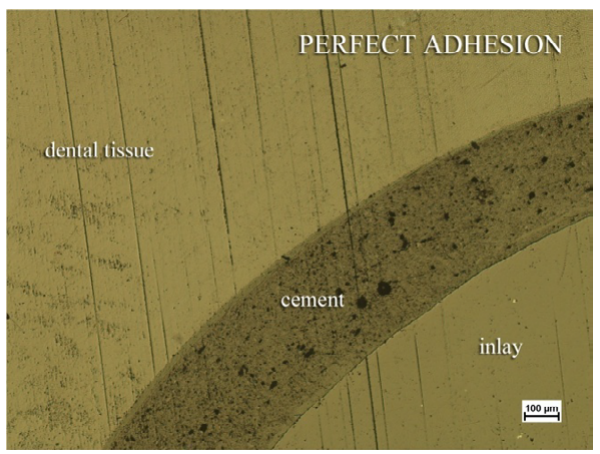

Figure 2: Perfect bonding of ceramic and tooth structures.

The pictures generated using microscope software show hybrid layer gaps (Figure 1) or a perfect bond (Figure 2).

\section{Results}

In this study the areas of leakage occurring at the bonding of cement to both the dental hard tissue and ceramic were measured in each of the experimental groups. The obtained results are an arithmetic average (Table 2). Standard deviations are high which indicates low predictability of measured materials. (Tables 3 and 4 ).

Based on the Kruskal-Wallis test, there are statistically significant differences in hybrid layer gaps of tooth-cement bonding which occurred when Rely X U200 Auto mix cement was used in comparison with other materials. As statistics reveal there are no significant discrepancies in hybrid layer gaps of ceramic-cement bonding between experimental groups. Those results are presented in Tables 3 and 4 . In order to understand it right, one should know that in this statistic method if $\mathrm{P}$ is lower than 0,05 , there is a significant difference between measured parameters.

The outcome of this study indicates differences in the adhesion of the cement to both the dental hard tissue and ceramics. Next, the result analysis helps determine that the tightest bonding between dental hard tissue and cement was obtained using Rely X Ultimate Clicker with self-etching Single Bond Universal, though its adhesion to ceramic is the least satisfactory of the systems used (Figure 3). On the contrary, self-adhesive cement adhered well to ceramic (Figure 4), however its bonding with the tooth structure showed significant leaks (Figure 5). Moreover, only when Multilink Auto mix was applied together with Monobond Plus was the tightest bonding with ceramics and optimal 
Citation: Rączkiewicz M, Rosochacka A, Zasada D, Mazurek K (2015) Evaluation of Ceramic Inlay Leakage Cemented with Adhesive Materials. An In Vitro Study. J Bioengineer \& Biomedical Sci 6: 173. doi:10.4172/2155- 9538.1000173

Page 3 of 5

\begin{tabular}{|l|c|c|}
\hline & $\begin{array}{c}\text { Aritmetic Average of The } \\
\text { Tooth-Cement Bonding }[\boldsymbol{\mu M}] \\
\text { (Standard Deviation) }\end{array}$ & $\begin{array}{c}\text { Arithmetic Average of The } \\
\text { Ceramics-Cement Bonding } \\
{[\boldsymbol{\mu m}] \text { (Standard Deviation) }}\end{array}$ \\
\hline Multilik Automix & 10050,5 & 551,8 \\
& $(1409,1)$ & $(549,7)$ \\
\hline Rely X Ultimate & 7402,7 & 116322,5 \\
Clicker & $(23403,5)$ & $(330753,8)$ \\
\hline Rely X U200 & 146089,2 & 6460,5 \\
Automix & $(198468,2)$ & $(10021,5)$ \\
\hline
\end{tabular}

Table 2: Obtained results.

\begin{tabular}{|l|c|c|c|}
\hline & $\begin{array}{c}\text { Rely X U200 } \\
\text { Automix }\end{array}$ & Multilink Automix & $\begin{array}{c}\text { Rely X Ultimate } \\
\text { Clicker }\end{array}$ \\
\hline Rely X U200 Automix & & 0,011 & 0,000 \\
\hline Multilink Automix & 0,011 & & 0,511 \\
\hline Rely X Ultimate Clicker & 0,000 & 0,511 & \\
\hline
\end{tabular}

Table 3: $P$ values - hybrid layer gaps tooth-cement bonding.

\begin{tabular}{|l|c|c|c|}
\hline & $\begin{array}{c}\text { Rely X U200 } \\
\text { Automix }\end{array}$ & $\begin{array}{l}\text { Multilink } \\
\text { Automix }\end{array}$ & $\begin{array}{c}\text { Rely X Ultimate } \\
\text { Clicker }\end{array}$ \\
\hline Rely X U200 Automix & 0.476 & 0.476 & 1.000 \\
\hline Multilink Automix & 1.000 & 0.220 & 0.220 \\
\hline $\begin{array}{l}\text { Rely X Ultimate } \\
\text { Clicker }\end{array}$ & & & \\
\hline
\end{tabular}

Table 4: $P$ values-hybrid layer gaps ceramic-cement bonding.

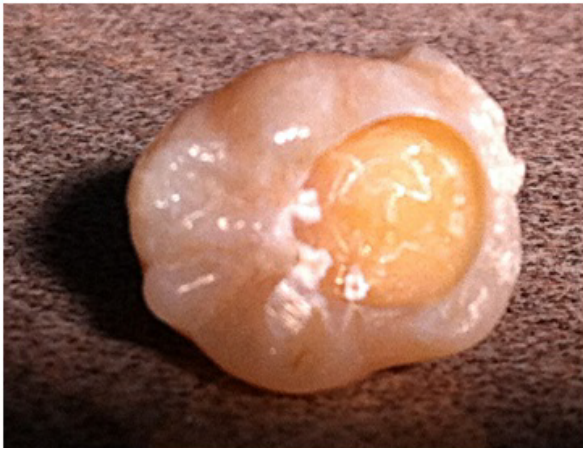

Figure 3: Third molar with cylider shaped Black's class first cavity.

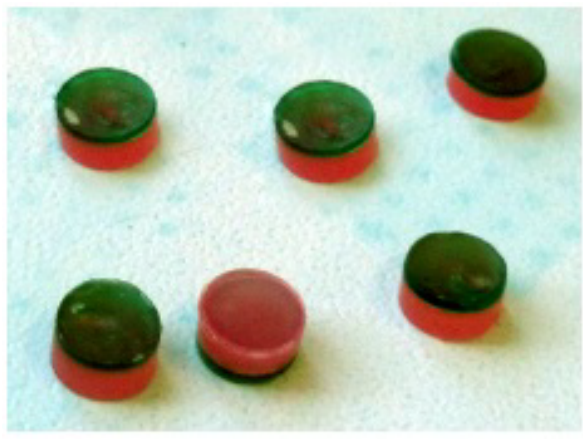

Figure 4: The inlay molds made of modeling wax.

bonding with tooth structure observed (Figure 6). Also, when Multilink Auto mix was used, standard deviation was lowest which means that it is the most predictable system in the study.
In our study, the ceramic surface was etched with $10 \%$ hydrofluoric acid when Multilink Automix and Rely X Ultimate systems were used. Then Monobond Plus and Single Bond Universal were used respectively, in order to create the chemical bonding. When Rely X U200 Auto mix self-adhesive cement was used, the ceramic was not prepared in any way, according to the manufacturer's instructions. These approaches are recommended by the manufacturers of bonding systems and accepted by Ivoclar Vivadent who produces the IPS e.max ceramic (Figures 7-10).

\section{Discussion}

The hybrid layer created by adhesive systems is responsible for

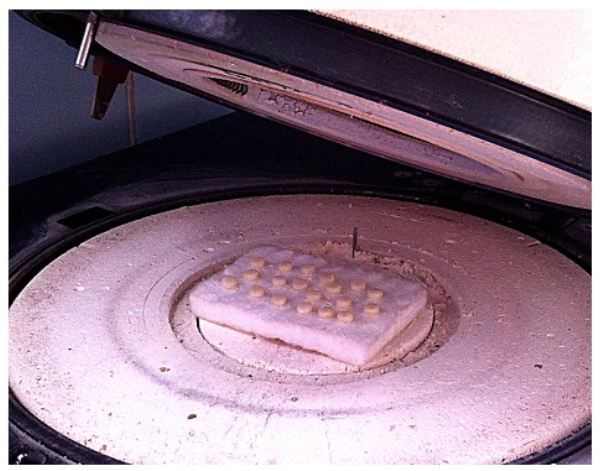

Figure 5: Glaze firing process.

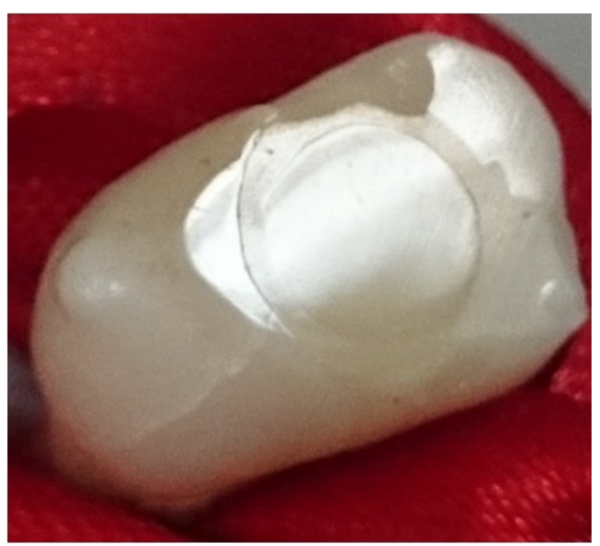

Figure 6: Tooth after polishing

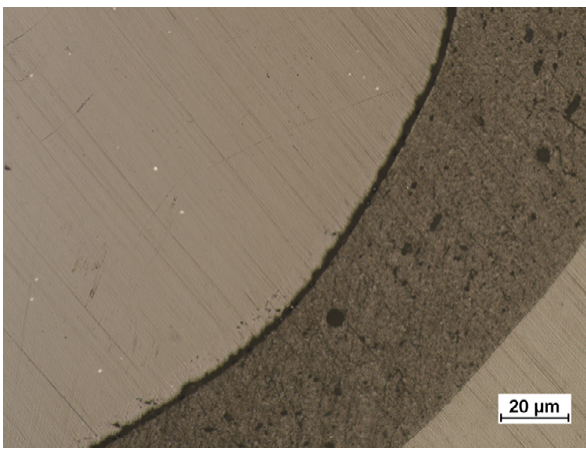

Figure 7: Rely X Ultimate Clicker bonding with ceramic and tooth structure. 


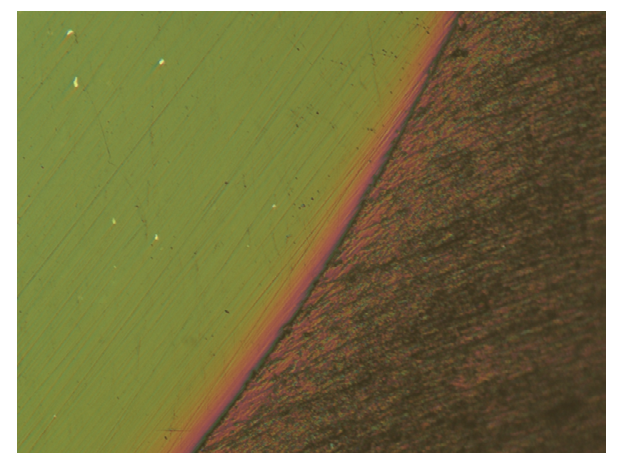

Figure 8: Rely X U200 Automix cement bonding with ceramic.

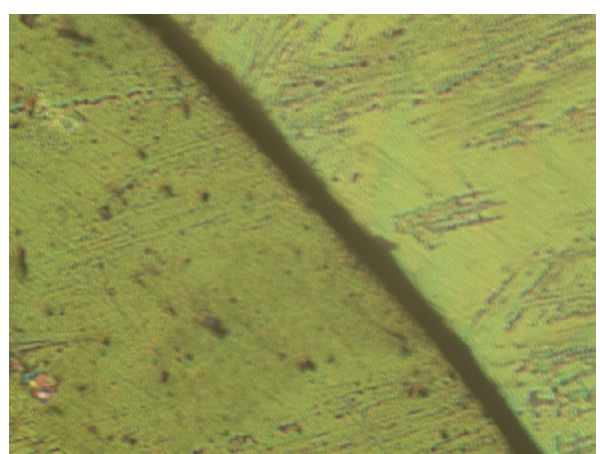

Figure 9: Rely X U200 Automix cement bonding with tooth structure.

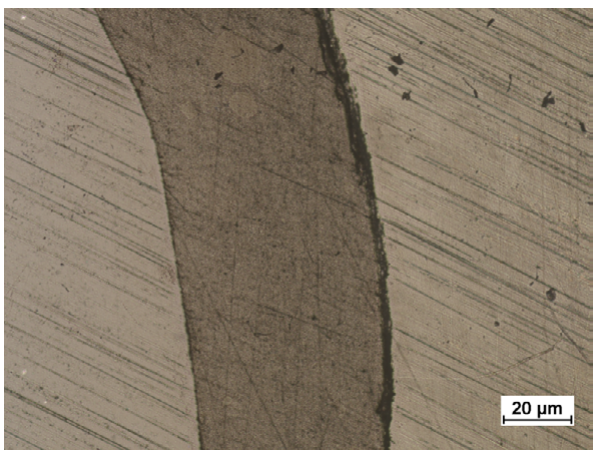

Figure 10: Multilink automix cement bonding ceramic and tooth structure.

the sustainability of the connection between dental hard tissues and ceramics [6]. It is well known that proper hybridization improves the bond strength. However, leaks between the collagen fibrils and the resin ingredients may lead to formation of microleakage [7]. This is defined as the passage of bacteria, fluids, molecules or ions between tooth and the restoration [8]. Leakage is caused by acid etching of dentine, which does not result in homogeneous demineralization - there are even places where the surface is not etched at all [9]. This is the reason why the infiltration of resin into the collagen fibrillary matrix is incomplete. Pashley et al. claims that this is caused by water, which is used to rinse acid, and it is never perfectly replaced by the resin in dentinal tubules [10]. Moreover, during dentinogenesis odontoblasts secrete matrix metalloproteinases (MMPs) [11]. The acidic environment, which occurs while there are on-going caries processes or might be created while using the adhesive systems, activates these proteases. MMPs are involved in demotion of the exposed collagen fibrils. Berschi et al. proved that the destructive activity of MMPs may be decreased by reducing microleakage [12]. Gaps, which are an effect of insufficient sealing, can result in marginal discoloration, secondary caries, and pulpitis [13]. This is why microleakage is a determining factor by which dentists and researchers can predict the performance of the restoration [14].

Nowadays, clinical practitioners are most afraid of the techniquesensitive adhesives which demand step-by-step procedures during which the smallest mistake may mean failure [12]. However, it seems that a multiplicity of stages provides a more stable connection with the tooth structure [15]. It is also a result of the present study, in which one-bottle Rely X Ultimate Clicker with selective acid-etching of enamel showed the best efficiency in creating a bond with tooth tissues.

The study presented aimed to provide information on which of the used systems creates the most homogenous bond with tooth structure surfaces as well as with ceramics.

Acid etching of the ceramics surface selectively removes the glassy matrix, and exposes crystalline structures which enables the achievement of proper texture and roughness [16]. IPS e.max Press is a lithium disilicate glass-ceramic which can be etched with hydrofluoric acid and treated with adhesives for creating a micromechanical bond. Permanent bonding is achieved if the resin is able to penetrate the microretensions deeply [17]. In order to gain the most favorable results, the systems which were used to prepare dental tissues were used with compatible systems to prepare the ceramic surface. Therefore, Multilink's Monobond Plus was used in conjunction with Multilink Auto mix with its adhesive system, and 3M's Single Bond Universal was used in conjunction with 3M's Rely X Ultimate Clicker. While using 3M's Rely X U200 Auto mix, the ceramic must not be treated in any way.

The results of our study comply with Toress' opinion that application technique is the significant factor that determines the quality of bonding [18]. Self-etching systems present satisfactory bonding with dentine, however their bonding with enamel exhibits low quality [18]. This is the reason why manufacturers recommend selective etching of enamel. This is the way we proceeded while using Rely X Ultimate Clicker and as the results of our study show, it is the best solution for creating bonding with dental hard tissues.

Other research was focused on the quality of the bonding created by self-etching, self-adhesive cement [19]. Similarly to the results of this study, Behrs et al. results showed a lower percentage of 'perfect margin' between cement and dentine than the interface between cement and ceramics. Furthermore, this study admits that multistep procedures create higher quality bonding than self-adhesive cements [19]. Additionally, transmission electron microscopy images revealed that self-adhesive cement does not create a high quality hybrid layer in comparison to the one created by total etch systems [19]. The same opinion is provided by Lührs et al. based on clinical studies which confirm higher quality of bonding created by conventional cements [20].

Resin cements may be divided based on the way they polymerize into three groups: chemically cured, light-cured, and dual-cured. The long setting time is required while using chemically cured cement and it also does not allow control of the working time [21]. On the other hand, light does not penetrate deeply enough through ceramics to achieve proper polymerization [22]. All the cements used in our study were dual-cured. They provide the best control during cementation and allow the areas that cannot be penetrated by the light to be cured, 
Citation: Rączkiewicz M, Rosochacka A, Zasada D, Mazurek K (2015) Evaluation of Ceramic Inlay Leakage Cemented with Adhesive Materials. An In Vitro Study. J Bioengineer \& Biomedical Sci 6: 173. doi:10.4172/2155- 9538.1000173

especially while fixing an inlay [21]. Large results of standard deviation may be caused by the low number of samples. This is the reason why the study will be continued and expanded.

Practitioners must remember that clinically after cementing both the tooth and the restoration, the tooth is immediately susceptible to bacterial invasion, load, and temperature fluctuations. This evaluation presents how to minimize the inevitable effects.

\section{Conclusions}

- $\quad$ Based on the comparative studies, it may be concluded that self-adhesive cements indicate significantly lower bonding quality in comparison to cements with separate own bonding systems.

- Despite more complex adhesive procedures, multistage bonding systems demonstrate better bonding.

Among the three studied cements, the material with selfetching Primer A $+B$ showed the best efficacy and therefore may be recommended in clinical practice.

\section{References}

1. Elżbieta MN (2011) Uzupełnienia ceramiczne. Postepowanie kliniczne wykonawstwo laboratoryjne. Med Tour Press International.

2. Manso AP, Silva NRFA, Bonfante EA, Peegoraro TA, Dias RA, et al. (2011) Cements and Adhesives for All-Ceramic Restorations. Dent Clinics of North America 55: 311-332.

3. Van Meerbeck B, Yoshiharaa K, Yoshidab Y, Minec A, De Munck J, et al (2011) State of the art of self-etches adhesives. Dental Mater 27: 17-28.

4. Ferracane $\mathrm{JL}$ (2005) Developing a more complete understanding of stresses produced in dental composites during polymerization. Dental Mater 21: 36-42.

5. Savarino L, Saponara Teutonico A, Tarabusi C, Breschi L, Prati C (2002) Enamel microhardness after in vitro demineralization and role of different restorative materials. J Biomater Sci Polym 13: 349-57.

6. Ding DGF, Wolff D, Pioch T, Staehle HJ, Dannewitz B (2009) Reltionship between microtensile bond strength and nanoleakage at the composite-dentin interface. Dental Mater 25: 135-141.

7. Hashimoto M, Ohno H, Endo K, Kaga M, Sano H, Oguchi H (2000) The effect of hybrid layer thickness on bond strength: demineralized dentin zone of the hybrid layer. Dental Mater 16: 406-411.
8. Kidd EAM (1976) Microleakage: A review. J Dent 4: 199-205.

9. Pashley DH, Tay FR, Breschi L, Tjäderhane L, Carvalho RM, et al. (2011) State of the art etch-and-rinse adhesives. Dental Mater 27: 1-16.

10. Almahdy A, Koller G, Sauro S, Bartsch JW, Sherriff M, et al. (2012) Effect of MMP Inhibitors Incorporated within Dental Adhesives. J Dens Res. 91: 605-611.

11. Breschi L, Martin P, Mazzoni A, Nato F, Carrilho M, et al. (2010) Use of a specific MMP-inhibitor (galardin) for preservation of hybrid layer. Dent Mater 26: 571-8.

12. Van Meerbeek B, De Munck J, Yoshida Y, Inoue S, Vargas M, et al. (2003) Buonocore, Memorial lecture. Adhesion to enamel and dentin: Current status and future challenges. Oper Dent 28: 215-35.

13. Fabianelli A, Pollington S, Davidson CL, Cagidiaco MC, Goracci C, (2007) The relevance of microleakage studies. Int Dent SA 9: 64-74.

14. Mali P, Deshpande S, Singh A (2006) Microleakage of restorative materials: An in vitro study. J of Indian Society of Pedodontics and Preventive Dentistry 24: $15-18$.

15. De Munck J, Van Landuyt K, Peumans M, Lambrechts P, et al. (2005) A critical review of the durability of adhesion to tooth tissue: methods and results. J Dent Res 84: 118-132.

16. Blatz MB, Sadan A, Kern M (2003) Resign-ceramic bonding: A review of the literature. J of Prosthet. Dentistry 89: 268-74.

17. Guerel G (2003) The science and art of porcelain laminate veneers. Quintessence Publishing Co. Itd Chicago.

18. Torres CR, Barcellos DC, Pucci CR, Lima G, Rodrigues CM, et al. (2009) Influence of Methods of application of self-etching adhesives systems on adhesive bond strenght to enamel. J Adhes Dent 11: 279-286.

19. Behr M, Rosentritt, Regent T, Lang R, Handel G (2004) Mariginal adaptation in dentin of self-adhesive universal resin cement compared with ewll tried systems. Denat Mater 20: 191-197.

20. Lührs AK, Guhr S, Günay H, Geurtsen W (2010) Shear bond strength of selfadhesive resins compared to resin cements with etch and rinse adhesives to enamel and dentin in vitro. Clin Oral Invest 14: 193-199.

21. Lee IB, An W, Chang J, Um CM (2008) Influence of ceramic thickness and curing mode on the polymerization shrinkage kinetics of dual-cured resin cements. Dental Mater 24: 1141-1147.

22. Flavio RH, Driscoll CF, Prestipino V, Masri R, von Fraunhofer JA (2004) Light transmission though all-ceramic dental materials: A pilot study. J of Prosthet. Dent. 91: 441-446. 